\title{
Clinical Study \\ Crevicular Fluid and Serum Concentrations of Progranulin and High Sensitivity CRP in Chronic Periodontitis and Type 2 Diabetes
}

\author{
N. Priyanka, ${ }^{1}$ Minal Kumari, ${ }^{1}$ Nitish Kalra, ${ }^{1}$ P. Arjun, ${ }^{2}$ Savitha B. Naik, ${ }^{3}$ and A. R. Pradeep ${ }^{1}$ \\ ${ }^{1}$ Department of Periodontics, Government Dental College and Research Institute, Bangalore, Karnataka 560002, India \\ ${ }^{2}$ Bangalore Medical College and Research Institute, Bangalore, Karnataka 560002, India \\ ${ }^{3}$ Department of Conservative Dentistry and Endodontics, Government Dental College and Research Institute, \\ Bangalore, Karnataka 560002, India
}

Correspondence should be addressed to A. R. Pradeep; periodonticsgdcri@gmail.com

Received 11 March 2013; Revised 13 June 2013; Accepted 4 August 2013

Academic Editor: Marco Peluso

Copyright (C) 2013 N. Priyanka et al. This is an open access article distributed under the Creative Commons Attribution License, which permits unrestricted use, distribution, and reproduction in any medium, provided the original work is properly cited.

\begin{abstract}
Introduction. This study was designed to correlate the serum and gingival crevicular fluid (GCF) levels of progranulin (PGRN) and high sensitivity C-reactive protein (hs CRP) in chronic periodontitis and type 2 diabetes mellitus (DM). Design. PGRN and hs CRP levels were estimated in 3 groups: healthy, chronic periodontitis, and type $2 \mathrm{DM}$ with chronic periodontitis. Results. The mean PGRN and hs CRP concentrations in serum and GCF were the highest for group 3 followed by group 2 and the least in group 1. Conclusion. PGRN and hs CRP may be biomarkers of the inflammatory response in type $2 \mathrm{DM}$ and chronic periodontitis.
\end{abstract}

\section{Introduction}

Chronic periodontitis is an infectious disease that involves a host immune inflammatory response in the periodontal tissues against the microorganisms present in dental plaque [1]. The clinical features of periodontitis include clinical attachment level (CAL), alveolar bone loss, periodontal pockets, and gingival inflammation [2]. Host immune inflammatory reactions are thought to protect the host against the infectious agents, but the persistent release of inflammatory mediators by immune cells results in the destruction of soft and mineralized periodontal tissues [3].

Periodontal inflammation has a significant impact on various systemic diseases with high prevalence, incidence, morbidity and mortality, for example, diabetes mellitus (DM) and cardiovascular diseases. Thus, preexisting periodontitis influences glycemic control and complication outcomes in diabetes patients. On the other hand, extensive epidemiological studies have shown that DM increases the risk of periodontal tissue damage $[4,5]$.

$\mathrm{DM}$, a chronic metabolic disease characterized by hyperglycemia, is often attributed to environmental and genetic factors. The prevalence of DM has risen dramatically in recent years, resulting in a rapid increase of diabetic patients. Asia in particular has the highest prevalence of diabetes in the world. Countries exhibiting the fastest rate in diabetic population growth include India and China, among many other developing countries [6].

Progranulin (PGRN), also called as granulin/epithelin precursor, proepithelin, PC cells-derived growth factor, and acrogranin, is a glycosylated protein released by a variety of cells [7]. PGRN is a 593-amino acid, cysteine-rich protein with an estimated molecular weight of $68.5 \mathrm{kDa}$ that runs at $90 \mathrm{kDa}$ on standard western blots due to heavy glycosylation [8]. Proteolytic cleavage of the precursor protein by extracellular proteases, such as elastase, gives rise to smaller peptide fragments termed granulins or epithelins [9]. These fragments range in size from 6 to $25 \mathrm{kDa}$ and have been implicated in a range of biological functions $[9,10]$. PGRN mRNA has been demonstrated in various tissues and organs including the reproductive organs, gastrointestinal tract, endocrinal organs, and neural tissues [11, 12]. It is particularly prominent in epithelial and hematopoietic cells 
and tends to be more highly expressed in tissues with high turnover rates such as gastric mucosa, lymphoid tissue, and tumor cell lines $[12,13]$.

PGRN has been also implicated in wound healing and inflammation [14-16]. Circulating PGRN significantly correlates with high sensitivity $\mathrm{C}$-reactive protein (hs-CRP) serum concentrations, A1C values, and total cholesterol. Multivariable linear regression analyses revealed CRP levels as the strongest independent predictor of circulating PGRN [17].

CRP is an extremely sensitive and nonspecific acutephase marker for inflammation that is produced in response to many forms of injury other than periodontitis, such as other infections, trauma, and hypoxia [18]. CRP presents associations with smoking, obesity, coffee consumption, triglycerides, diabetes, and periodontal disease $[19,20]$. CRP and interleukin-6 (IL-6) are reported to be significant risk indicators for the development or progression of DM [21].

A study suggests a close coregulation between CRP and PGRN serum concentration and demonstrated that PGRN may be a novel biomarker of the chronic inflammatory response in type $2 \mathrm{DM}$ and associated disturbances [17]. Hence, PGRN is an important molecule in inflammatory response and could therefore be involved in chronic subclinical inflammation associated with type $2 \mathrm{DM}$ and chronic periodontitis.

However, till date, PGRN and hs-CRP concentration in serum and GCF in type 2 DM subjects with chronic periodontitis has not been explored. Hence, the aim of the present study is to assess the concentration of PGRN and hsCRP in serum and GCF of type 2 DM subjects with chronic periodontitis to find their association, if any.

\section{Materials and Methods}

The study was carried out from November 2011 to February 2012. The study group consisted of 40 , age and gender balanced subjects (25-45 years; gender: 20 males and 20 females) attending the outpatient section, Department of Periodontics, Government Dental College and Research Institute, Bangalore. Written informed consent was obtained from those who agreed to participate voluntarily. The Ethical Clearance was approved by the Institutional Ethical Committee and Review Board.

2.1. Inclusion Criteria. Subjects should be in the age group of 25-45 years with the presence of at least 20 natural teeth; subjects should be with a diagnosis of chronic periodontitis based on clinical parameters like probing depth (PD), clinical attachment level (CAL) [22], gingival index (GI) [23]. A body mass index should be (BMI) in range of $18.5-22.9 \mathrm{~kg} / \mathrm{m}^{2}$ and waist circumference $<90 \mathrm{~cm}$ (men) and $<80 \mathrm{~cm}$ (women) [24]; subjects should not have received periodontal therapy within preceding six months; Well-controlled type 2 diabetic patients classified based on criteria given by the American Diabetic Association (ADA) in 2010 and glycated hemoglobin levels [25].
2.2. Exclusion Criteria. Subjects with aggressive periodontitis, hypertension, a smoking habit, gross oral pathology, heart diseases rheumatoid arthritis, tumors, or any other systemic disease that can alter the course of periodontal disease, or those who had any course of medication affecting periodontal status or had received periodontal therapy in the preceding 6 months were excluded from the study.

2.3. Grouping Criteria. Group 1 (healthy) consisted of 10 subjects with clinically healthy periodontium, GI $=0$ (absence of clinical inflammation), $\mathrm{PD} \leq 3 \mathrm{~mm}$, and $\mathrm{CAL}=0$, with no evidence of bone loss on radiographs. Group 2 (chronic periodontitis subjects) consisted of 15 subjects who had signs of clinical inflammation, GI $>1$, greater than $30 \%$ sites had $\mathrm{PD} \geq 5 \mathrm{~mm}$, and CAL $\geq 3 \mathrm{~mm}, \mathrm{HbAlc} \leq 7 \%$ with radiographic evidence of bone loss. Group 3 (chronic periodontitis subjects with type $2 \mathrm{DM}$ ) consisted of 15 subjects who had signs of clinical inflammation, GI $>1$, greater than $30 \%$ sites had PD $\geq 5 \mathrm{~mm}$, and CAL $\geq 3 \mathrm{~mm}$, with radiographic evidence of bone loss. Only well-controlled (HbAlc $\leq 7 \%)$ type $2 \mathrm{DM}$ subjects were selected based on ADA's criteria for diagnoses of diabetes.

2.4. Clinical Evaluation of Subjects. Group allocations and sample site selections were performed by the chief coordinator (ARP). A calibrated examiner (PN) did the clinical evaluation measuring the clinical parameters including PD, CAL, and GI, using a University of North Carolina-15 periodontal probe (Hu-friedy, Chicago, IL, USA). The same examiner (PN) also did the radiographic evaluation and collected the GCF samples.

2.5. Site Selection and GCF Collection. Two test sites for GCF sample collection were selected based on the highest scored sites in the oral cavity. In group 3 and group 4 subjects, the 2 sites showing the greatest CAL and signs of inflammation, along with radiographic confirmation of bone loss, were selected for sampling. One of the 2 sites selected/subject was used for hs-CRP while the other for PGRN analysis. In the healthy group, to standardize site selection and obtain adequate fluid volume, sampling was predetermined to be from the mesiobuccal region of the maxillary right first molar, in the absence of which the left first molar was sampled. First, the selected site was cleaned, isolated, and air dried using sterile cotton rolls, and the supragingival plaque was removed gently using a Universal gracey curette \#4R/4L ( $\mathrm{Hu}-$ friedy, Chicago, IL, USA) to avoid contamination of the paper strips. The paper strips (Periopaper, Ora Flow Inc., Amityville, NY USA) were placed gently at the entrance of the gingival sulcus/crevice until the light resistance was felt [26], care being taken to avoid mechanical injury, and left in place for 60 seconds. The absorbed GCF volume of each strip was determined by electronic impedance (Periotron 8000, ProFlow Inc., Amityville, NY, USA). Samples that were suspected to be contaminated with blood and saliva were excluded from the study. After collection of the gingival fluid, the two periopaper strips/site that absorbed GCF from each subject were pooled and were immediately transferred 
in microcentrifuge tubes (premarked with the biomarker name) containing $400 \mu \mathrm{L}$ of phosphate buffer saline and stored frozen at $-70^{\circ} \mathrm{C}$ for subsequent analysis. Periodontal treatment (scaling and root planning) was performed for $\mathrm{CP}$ subjects at the same appointment after GCF collection by the operator $(\mathrm{NK})$.

2.6. Blood Collection. Two milliliters of blood was collected from the antecubital fossa by venipuncture using a 20 -gauge needle with $2 \mathrm{~mL}$ syringe and immediately transferred to the laboratory. The blood sample was allowed to clot at room temperature, and after 1 hour serum was separated from blood by centrifuging at $3000 \mathrm{rpm}$ for $5 \mathrm{~min}$. The serum was immediately transferred to a plastic vial and stored at $-70^{\circ} \mathrm{C}$ until the time of assay.

2.7. PGRN Analysis. The samples were assayed for PGRN using enzyme-linked immunosorbent assay (ELISA) kit according to manufacturer's instructions (Adipogen International Inc, Incheon, South Korea). The GCF sample tubes were first homogenized for 30 seconds and centrifuged for 5 minutes at 1,500 $\mathrm{g}$ to elute. The elute was then used as sample for ELISA estimation from GCF samples. A polyclonal antibody specific for human PGRN had been precoated onto 96 well microplate. Standards and samples were pipetted into the wells, and any PGRN present was bound byimmobilized antibody. Bound PGRN was captured by biotinylated antihuman PGRN polyclonal antibody. HRP conjugated streptavidin was added. After washing, a substrate solution was added. The colors developed in proportion to the bounded PGRN quantity. Colour development was monitored using a microplate reader until an optimum optical density was reached, a stop solution was added, and the optical density was read at $450 \mathrm{~nm}$. The total PGRN was determined in nanograms (ng), and the calculation of the concentration in each sample was performed by dividing the amount of PGRN by the volume of sample $(\mathrm{ng} / \mathrm{mL})$.

2.8. hs-CRP Analysis. The samples for CRP were measured immunoturbidimetrically using RANDOX analyser. The microcentrifuge tubes containing the periopaper strips and plastic vials containing serum were transferred to the lab for immunoturbidimetric analysis. Serum was used undiluted. The measuring range of CRP is $0-220 \mathrm{mg} / \mathrm{L}$, with the normal value of CRP being $<5 \mathrm{mg} / \mathrm{L}$ [27].

\section{Statistical Analysis}

All data were analyzed using a software program (SPSS Inc. version 17.1, Chicago, IL, USA). Test for the validity of normality assumption using standardized range statistics was carried out, and it was found that the assumption is valid. Analysis of variance (ANOVA) was carried out for a comparison of GCF and serum levels of PGRN between the groups. Using Pearson's correlation coefficient, the relationship between PGRN levels and clinical parameters was analyzed using a software program. $P$ values $<0.05$ were considered statistically significant.
TABLE 1: Descriptive Statistics of study population (mean \pm S.D.).

\begin{tabular}{lccc}
\hline Study group & $\begin{array}{c}\text { Group 1 } \\
(n=10)\end{array}$ & $\begin{array}{c}\text { Group 2 } \\
(n=15)\end{array}$ & $\begin{array}{c}\text { Group 3 } \\
(n=15)\end{array}$ \\
\hline Age (in years) & $34.22 \pm 3.43$ & $32.11 \pm 3.21$ & $33.12 \pm 3.03$ \\
Sex (M/F) & $5 / 5$ & $8 / 7$ & $7 / 8$ \\
GI & - & $2.21 \pm 0.54$ & $2.15 \pm 0.51$ \\
PD & $2.42 \pm 0.32$ & $7.33 \pm 1.32$ & $8.12 \pm 1.76$ \\
CAL & $2.31 \pm 0.12$ & $6.34 \pm 1.22$ & $6.55 \pm 1.52$ \\
Serum PGRN (ng/mL) & $76.3 \pm 2.34$ & $197.3 \pm 2.55$ & $255.4 \pm 2.65$ \\
GCF PGRN $(\mathrm{ng} / \mathrm{mL})$ & $72.5 \pm 2.11$ & $183.6 \pm 2.35$ & $239.2 \pm 2.42$ \\
Serum hs-CRP (mg/L) & $1.9 \pm 0.34$ & $3.55 \pm 0.14$ & $5.59 \pm 0.25$ \\
GCF hs-CRP $(\mathrm{mg} / \mathrm{L})$ & $0.61 \pm 0.13$ & $0.86 \pm 0.55$ & $1.34 \pm 0.22$ \\
\hline
\end{tabular}

\section{Results}

The descriptive statistics along with the mean \pm SD of both serum and GCF (of all groups) are tabulated in Table 1. The mean hs-CRP and PGRN concentrations both in serum and GCF were the highest for group 3 followed by group 2 and the least in group 1. To find out the equality of means between the three groups, ANOVA test was carried out (Table 2). A significant difference in the serum and GCF levels of hs-CRP and PGRN was found between the 3 groups. The serum and GCF levels of PGRN were found to be significantly correlated $(P<0.05)$ to $\mathrm{PD}$ in groups 2 and 3 . The serum levels of hsCRP were found to be significantly correlated $(P<0.05)$ to PD in group 3. The GCF levels of hs-CRP were found to be significantly correlated $(P<0.05)$ to $\mathrm{PD}$ in group 2 . Pearson, correlation coefficient test was applied to evaluate the correlation between serum levels of hs-CRP and serum levels of PGRN and also for their GCF values. Table 3 shows the correlation coefficients and $P$ values. The correlations of the GCF and serum levels of the two biomarkers with clinical parameters are presented in Tables 4 and 5.

\section{Discussion}

Periodontal disease has been proposed as the sixth complication of diabetes, based on the highly frequent presence of both diseases in the same patient $[28,29]$. Studies [3032] showed that the prevalence and severity of periodontal disease are high in patients with DM. The putative theory is that the accumulation of advanced glycation end products induces the formation of proinflammatory cytokines (such as IL-1b) in hyperglycemia, and the cytokine-induced low-grade inflammation plays an essential role in the development of insulin resistance, which is a hallmark of type $2 \mathrm{DM}$ [33] and is involved in the destructive process of periodontitis [34]. Likewise, periodontal pathogens secrete endotoxin that may increase the amount of inflammation markers, such as CRP, tumor necrosis factor alpha, and IL-6 [35, 36]. This study evaluated the serum and GCF concentrations of PGRN and hs-CRP that can be used as a marker of periodontal disease as well as a risk indicator for DM.

CRP levels were generally high in the group 2 and 3 . This was reported to represent a higher DM risk for groups 
TABLE 2: Results of ANOVA comparing the mean serum and GCF PGRN concentrations. between three groups.

\begin{tabular}{|c|c|c|c|c|c|c|c|c|}
\hline \multirow{3}{*}{ Study groups } & \multicolumn{4}{|c|}{ PGRN } & \multicolumn{4}{|c|}{ hs-CRP } \\
\hline & \multicolumn{2}{|c|}{ Serum } & \multicolumn{2}{|c|}{ GCF } & \multicolumn{2}{|c|}{ Serum } & \multicolumn{2}{|c|}{ GCF } \\
\hline & $F$-value & $P$ value & $F$-value & $P$ value & $F$-value & $P$ value & $F$-value & $P$ value \\
\hline \multicolumn{9}{|l|}{ Group 1} \\
\hline Group 2 & 248.1 & $<0.001^{*}$ & 215.2 & $<0.001^{*}$ & 112.4 & $<0.001^{*}$ & 25.4 & $<0.001^{*}$ \\
\hline Group 3 & & & & & & & & \\
\hline
\end{tabular}

* Significant at $P$ value $<0.001$.

TABLE 3: Correlation of serum and GCF PGRN and hs-CRP in each group using Spearman's rank correlation coefficient test.

\begin{tabular}{lcccc}
\hline Group & $\begin{array}{c}\text { Serum } \\
\text { Correlation } \\
\text { coefficient }\end{array}$ & $P$ value & $\begin{array}{c}\text { Correlation } \\
\text { coefficient }\end{array}$ & $P$ value \\
\hline Group 1 & 0.36526 & NS & -0.52301 & NS \\
Group 2 & 0.12322 & $0.000^{*}$ & 0.46548 & NS \\
Group 3 & -0.46878 & NS & -0.23332 & NS \\
\hline
\end{tabular}

${ }^{*}$ Significant at $P$ value $<0.05$.

NS: not significant.

TABLE 4: Relationship of PGRN to clinical parameters.

\begin{tabular}{ccccc}
\hline & Parameters & Group 1 & Group 2 & Group 3 \\
\hline \multirow{4}{*}{ Serum } & GI & - & 0.4234 & 0.7652 \\
& PD & 0.3212 & $0.0068^{*}$ & $0.0088^{*}$ \\
& CAL & 0.0572 & $0.0325^{*}$ & $0.0322^{*}$ \\
\multirow{4}{*}{ GCF } & GI & - & 0.5124 & 0.7826 \\
& PD & 0.2246 & $0.0005^{*}$ & $0.0082^{*}$ \\
& CAL & 0.4235 & 0.0687 & $0.0422^{*}$ \\
\hline
\end{tabular}

${ }^{*}$ Significant at $P$ value $<0.05$.

TABle 5: Relationship of hs-CRP to clinical parameters.

\begin{tabular}{lcccc}
\hline & Parameters & Group 1 & Group 2 & Group 3 \\
\hline \multirow{4}{*}{ Serum } & GI & - & 0.8484 & 0.8261 \\
& PD & 0.7456 & $0.0038^{*}$ & 0.4261 \\
& CAL & 0.2384 & 0.0927 & 0.5231 \\
\multirow{3}{*}{ GCF } & GI & - & 0.0854 & 0.2235 \\
& PD & 0.2667 & 0.2877 & 0.0665 \\
& CAL & $0.0000^{*}$ & 0.1667 & $0.0242^{*}$ \\
\hline
\end{tabular}

* Significant at $P$ value $<0.05$.

with chronic periodontitis and groups without it. However, because the group with chronic periodontitis showed CRP levels greater than the levels in the group without chronic periodontitis, it is possible that a greater activity of periodontitis may have been responsible for these differences, particularly among individuals with a profile of high degrees of inflammation.

PGRN is a multifunctional protein that has gained attention in the neuroscience field, because of the discovery that frontotemporal dementia is associated with PGRN mutations in some subjects [37]. The physiological function of PGRN is complex, with the full-length form of the protein having trophic and anti-inflammatory activity, whereas proteolytic cleavage generates granulin peptides that promote inflammatory activity [38]. In the periphery, PGRN promotes wound healing by increasing the accumulation of neutrophils, macrophages, and other cells in wounds [15]. PGRN plays a role in the association between obesity, type 2 diabetes, and inflammatory response.

ELISA estimation of serum and GCF PGRN levels was done, and hs CRP concentrations were estimated by immunoturbidimetry method. PGRN and hs-CRP serum and GCF concentrations are not different in men and women and do not seem to be age dependent. PGRN and hs CRP levels correlate with PD and CAL. The results of the present study indicated that concentrations of PGRN and hs CRP in serum and GCF increased progressively from healthy to periodontitis sites, while in periodontitis sites in diabetes subjects the mean concentration of PGRN was higher than the concentrations obtained in groups 1 and 2, suggesting that these markers reflect chronic inflammation as the periodontal disease advances from health to chronic periodontitis, and their levels are much higher in chronic periodontitis subjects with DM. The results of the present study are in accordance with those of previous study in which serum PGRN levels were elevated in diabetic subjects [17]. The increase in serum and GCF concentrations of hs-CRP from health to chronic periodontitis to chronic periodontitis with DM in the present study is in accordance with a previous study [39]. We further found significant relationship between PGRN and hs-CRP concentrations. In a recently conducted cross sectional study, the levels of PGRN and hs-CRP were assessed in serum and GCF of obese and health individuals with and without periodontitis. We found that the levels of these two inflammatory markers were the highest in obese periodontitis subjects followed by nonobese chronic periodontitis individuals and the least in nonobese individuals [40]. This is the first study evaluating and correlating hs-CRP and PGRN in chronic periodontitis with and without DM, and our data therefore suggest an association between CRP and PGRN levels and demonstrate that PGRN and hs CRP may be biomarkers of the chronic inflammatory response in $\mathrm{DM}$ and chronic periodontitis.

\section{Conclusion}

Thus within the limits of the current study, PGRN and hs-CRP levels may be markers of chronic inflammatory response in chronic periodontitis and type 2 DM. Further 
longitudinal prospective studies involving a larger population are needed to confirm the findings of the present study, to better understand the role of these markers in the pathogenesis, and also to address the clinical implication and pathological mechanism of the markers in periodontal disease progression.

\section{Acknowledgment}

The authors acknowledge Mr. Manjunath Sharma, Statistician, Bangalore, India, for preparing the statistics. The authors report no potential conflict of interests.

\section{References}

[1] G. J. Seymour, E. Gemmell, R. A. Reinhardt, J. Eastcott, and M. A. Taubman, "Immunopathogenesis of chronic inflammatory periodontal disease: cellular and molecular mechanisms," Journal of Periodontal Research, vol. 28, no. 6, pp. 478-486, 1993.

[2] G. C. Armitage, "Periodontal diagnoses and classification of periodontal diseases," Periodontology 2000, vol. 34, pp. 9-21, 2004.

[3] G. J. Seymour, "Importance of the host response in the periodontium," Journal of Clinical Periodontology, vol. 18, no. 6, pp. 421-426, 1991.

[4] N. G. M. Chávarry, M. V. Vettore, C. Sansone, and A. Sheiham, "The relationship between diabetes mellitus and destructive periodontal disease: a meta-analysis," Oral Health \& Preventive Dentistry, vol. 7, no. 2, pp. 107-127, 2009.

[5] P. M. Preshaw, A. L. Alba, D. Herrera et al., "Periodontitis and diabetes: a two-way relationship," Diabetologia, vol. 55, no. 1, pp. 21-31, 2012.

[6] Chinese Diabetes Association, "China guideline for type 2 diabetes," 2007.

[7] A. Bateman and H. P. J. Bennett, "Granulins: the structure and function of an emerging family of growth factors," Journal of Endocrinology, vol. 158, no. 2, pp. 145-151, 1998.

[8] R. Daniel, E. Daniels, Z. He, and A. Bateman, "Progranulin (acrogranin/PC cell-derived growth factor/granulin-epithelin precursor) is expressed in the placenta, epidermis, microvasculature, and brain during murine development," Developmental Dynamics, vol. 227, no. 4, pp. 593-599, 2003.

[9] Z. He and A. Bateman, "Progranulin (granulin-epithelin precursor, PC-cell-derived growth factor, acrogranin) mediates tissue repair and tumorigenesis," Journal of Molecular Medicine, vol. 81, no. 10, pp. 600-612, 2003.

[10] P. G. Parnell, J. Wunderlich, B. Carter, and J. Halper, “Transforming growth factor e: amino acid analysis and partial amino acid sequence," Growth Factors, vol. 7, no. 1, pp. 65-72, 1992.

[11] V. Bhandari, A. Giaid, and A. Bateman, "The complementary deoxyribonucleic acid sequence, tissue distribution, and cellular localization of the rat granulin precursor," Endocrinology, vol. 133, no. 6, pp. 2682-2689, 1993.

[12] R. Daniel, Z. He, K. P. Carmichael, J. Halper, and A. Bateman, "Cellular localization of gene expression for progranulin," Journal of Histochemistry and Cytochemistry, vol. 48, no. 7, pp. 9991009, 2000.

[13] G. Serrero and O. B. Ioffe, "Expression of PC-cell-derived growth factor in benign and malignant human breast epithelium," Human Pathology, vol. 34, no. 11, pp. 1148-1154, 2003.
[14] T. Zanocco-Marani, A. Bateman, G. Romano, B. Valentinis, Z.-H. He, and R. Baserga, "Biological activities and signaling pathways of the granulin/epithelin precursor," Cancer Research, vol. 59, no. 20, pp. 5331-5340, 1999.

[15] J. Zhu, C. Nathan, W. Jin et al., "Conversion of proepithelin to epithelins: roles of SLPI and elastase in host defense and wound repair," Cell, vol. 111, no. 6, pp. 867-878, 2002.

[16] Z. He, C. H. P. Ong, J. Halper, and A. Bateman, "Progranulin is a mediator of the wound response," Nature Medicine, vol. 9, no. 2, pp. 225-229, 2003.

[17] B.-S. Youn, S.-I. Bang, N. Klöting et al., "Serum progranulin concentrations may be associated with macrophage infiltration into omental adipose tissue," Diabetes, vol. 58, no. 3, pp. 627636, 2009.

[18] I. Glurich, S. Grossi, B. Albini et al., "Systemic inflammation in cardiovascular and periodontal disease: comparative study," Clinical and Diagnostic Laboratory Immunology, vol. 9, no. 2, pp. 425-432, 2002.

[19] M. Saito, T. Ishimitsu, J. Minami, H. Ono, M. Ohrui, and H. Matsuoka, "Relations of plasma high-sensitivity C-reactive protein to traditional cardiovascular risk factors," Atherosclerosis, vol. 167, no. 1, pp. 73-79, 2003.

[20] G. Tüter, B. Kurtis, and M. Serdar, "Evaluation of gingival crevicular fluid and serum levels of high-sensitivity C-reactive protein in chronic periodontitis patients with or without coronary artery disease," Journal of Periodontology, vol. 78, no. 12, pp. 2319-2324, 2007.

[21] A. D. Pradhan, J. E. Manson, N. Rifai, J. E. Buring, and P. M. Ridker, "C-reactive protein, interleukin 6, and risk of developing type 2 diabetes mellitus," Journal of the American Medical Association, vol. 286, no. 3, pp. 327-334, 2001.

[22] H. Löe, "The gingival index, the plaque index and the retention index systems," Journal of Periodontology, vol. 38, no. 6, pp. 610616, 1967.

[23] L. Glavind and H. Löe, "Errors in the clinical assessment of periodontal destruction," Journal of Periodontal Research, vol. 2, no. 3, pp. 180-184, 1967.

[24] World Health Organization, "The Asia-Pacific perspective. Redefining obesity and its treatment," International Diabetes Institute, 2000.

[25] "Executive summary: standards of medical care in diabetes2010: current criteria for the diagnosis of diabetes," Diabetes Care, vol. 33, pp. S4-S10, 2010.

[26] H. Loe and P. Holm-Pedersen, "Absence and presence of fluid from normal and inflamed gingivae," Periodontics, vol. 3, pp. 171-177, 1965.

[27] P. Ravishankaran and R. Karunanithi, "Clinical significance of preoperative serum interleukin-6 and C-reactive protein level in breast cancer patients," World Journal of Surgical Oncology, vol. 9, article 18, 2011.

[28] B. L. Mealey, "Diabetes and periodontal disease: two sides of a coin," Compendium of Continuing Education in Dentistry, vol. 21, no. 11, pp. 943-946, 2000.

[29] W. A. Soskolne, "Epidemiological and clinical aspects of periodontal diseases in diabetics," Annals of Periodontology, vol. 3, no. 1, pp. 3-12, 1998.

[30] D. Kinane and P. Bouchard, "Periodontal diseases and health: consensus report of the sixth European workshop on periodontology," Journal of Clinical Periodontology, vol. 35, no. 8, pp. 333337, 2008. 
[31] G. E. Salvi, B. Carollo-Bittel, and N. P. Lang, "Effects of diabetes mellitus on periodontal and peri-implant conditions: update on associations and risks," Journal of Clinical Periodontology, vol. 35, no. 8, pp. 398-409, 2008.

[32] M. J. Novak, R. M. Potter, J. Blodgett, and J. L. Ebersole, "Periodontal disease in hispanic Americans with Type 2 diabetes," Journal of Periodontology, vol. 79, no. 4, pp. 629-636, 2008.

[33] G. E. Salvi, J. D. Beck, and S. Offenbacher, "PGE2, IL-1 beta, and TNF-alpha responses in diabetics as modifiers of periodontal disease expression," Annals of Periodontology, vol. 3, no. 1, pp. 40-50, 1998.

[34] D. T. Graves and D. Cochran, "The contribution of interleukin1 and tumor necrosis factor to periodontal tissue destruction," Journal of Periodontology, vol. 74, no. 3, pp. 391-401, 2003.

[35] B. Noack, R. J. Genco, M. Trevisan, S. Grossi, J. J. Zambon, and E. de Nardin, "Periodontal infections contribute to elevated systemic C-reactive protien level," Journal of Periodontology, vol. 72, no. 9, pp. 1221-1227, 2001.

[36] B. G. Loos, J. Craandijk, F. J. Hoek, P. M. E. Wertheim-Van Dillen, and U. van Dder Velden, "Elevation of systemic markers related to cardiovascular diseases in the peripheral blood of periodontitis patients," Journal of Periodontology, vol. 71, no. 10, pp. 1528-1534, 2000.

[37] I. Gijselinck, J. van der Zee, S. Engelborghs et al., "Progranulin locus deletion in frontotemporal dementia," Human Mutation, vol. 29, no. 1, pp. 53-58, 2008.

[38] J. L. Eriksen and I. R. A. Mackenzie, "Progranulin: normal function and role in neurodegeneration," Journal of Neurochemistry, vol. 104, no. 2, pp. 287-297, 2008.

[39] A. R. Pradeep, S. R. G. Shiva Manjunath, and R. Kathariya, "Progressive periodontal disease has a simultaneous incremental elevation of gingival crevicular fluid and serum CRP levels," Journal of Investigative and Clinical Dentistry, vol. 1, pp. 133-138, 2010.

[40] A. Pradeep, N. Priyanka, M. Prasad, N. Kalra, and M. Kumari, "Assosciation of progranulin and high sensitivity CRP concentrations in gingival crevicular fluid and serum in chronic periodontitis subjects with and without obesity," Disease Markers, vol. 33, pp. 207-213, 2012. 


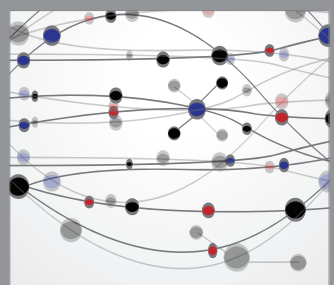

The Scientific World Journal
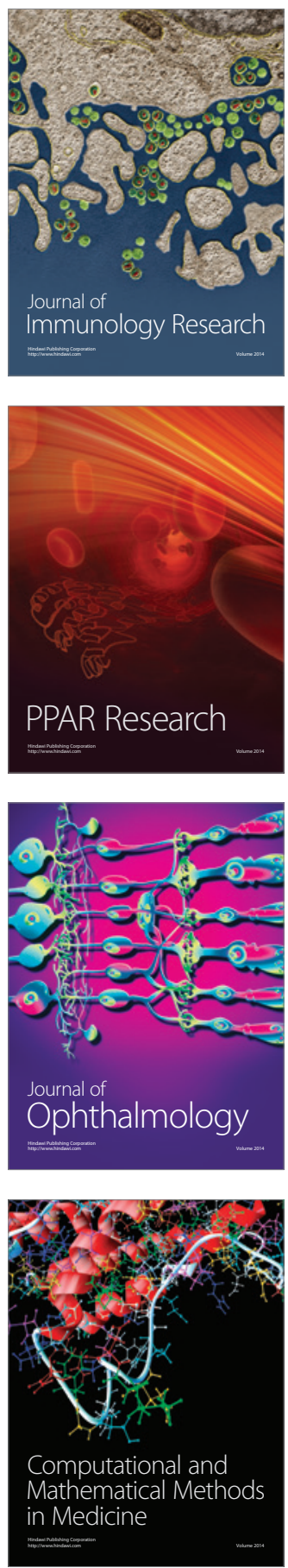

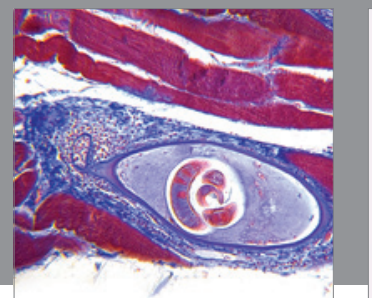

Gastroenterology

Research and Practice
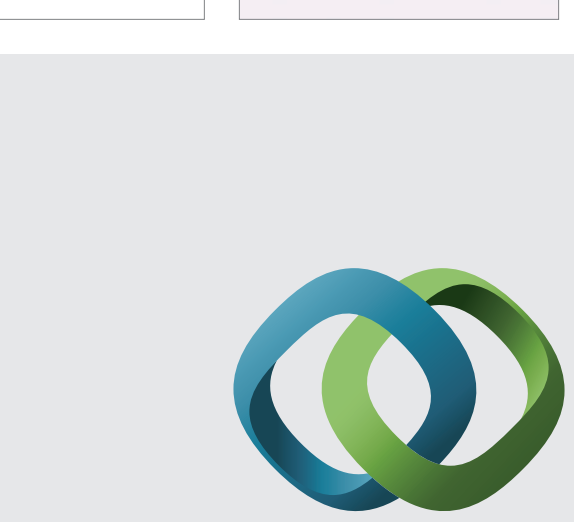

\section{Hindawi}

Submit your manuscripts at

http://www.hindawi.com
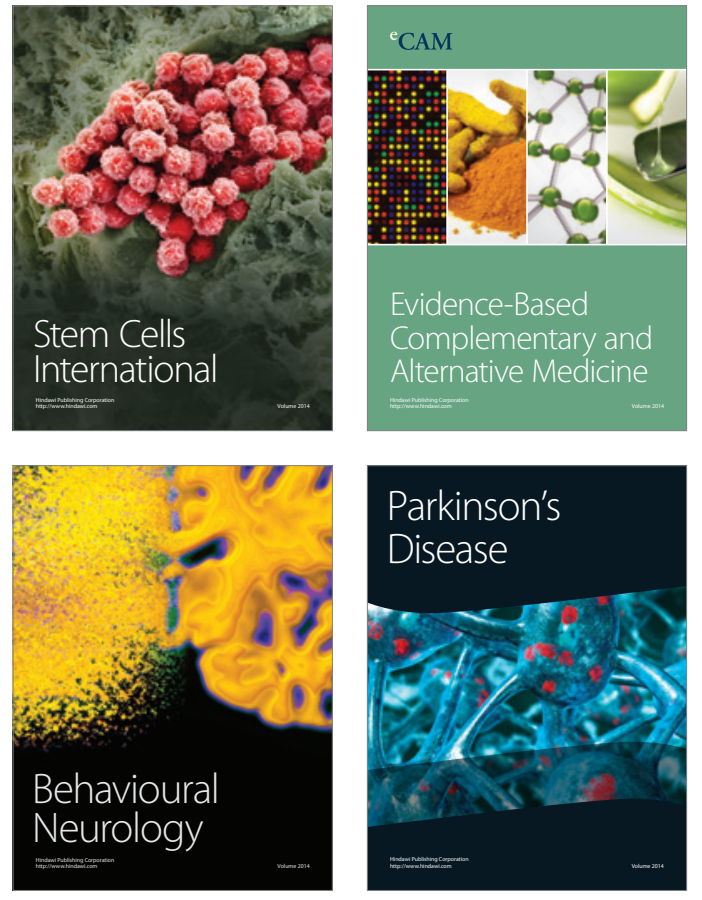
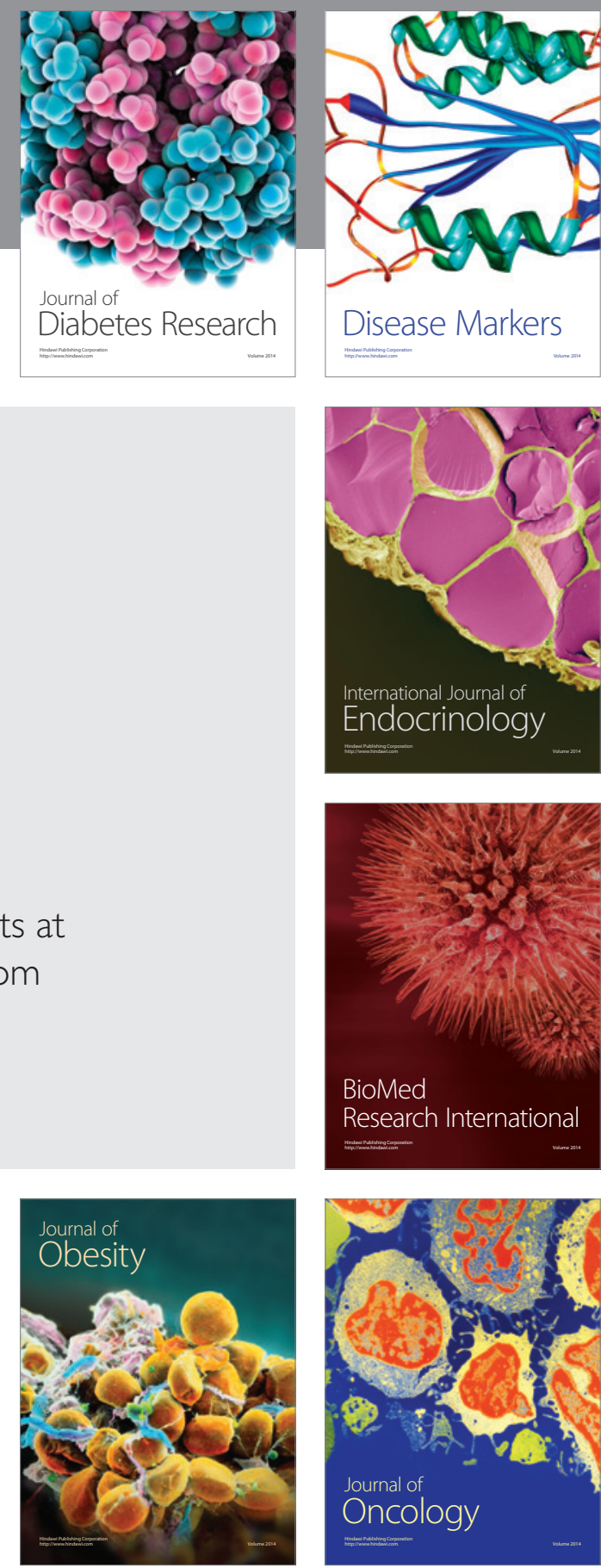

Disease Markers
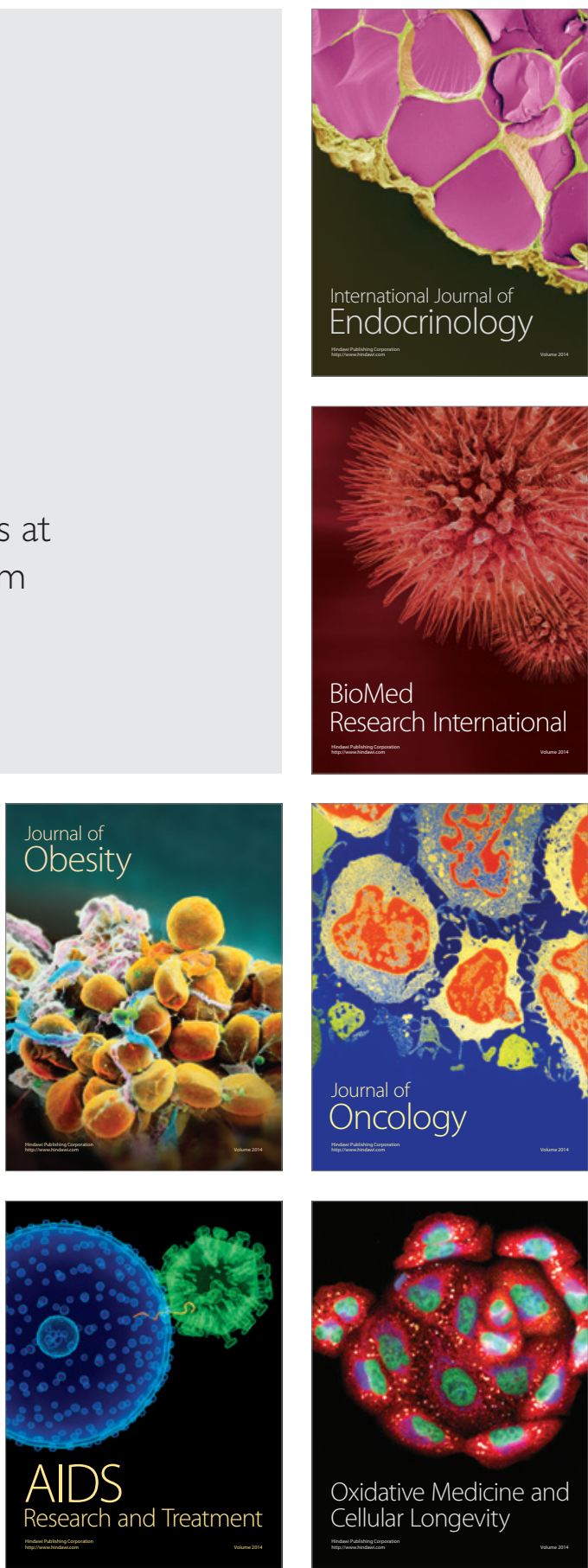